$\begin{aligned} & \text { Rocky problem } \\ & \text { Dispute flares up over } \\ & \text { access to Ethiopian } \\ & \text { fossil sites } \\ & p 728\end{aligned}$
$\begin{aligned} & \text { Astronomers in } \\ & \text { limbo over funding } \\ & \text { for telescope } \\ & p 729\end{aligned}$

\title{
Museum visitors take priority as Smithsonian curbs research
}

Josette Chen

The Smithsonian Institution in Washington DC, the world's largest museum complex, plans to close at least two of its research centres, with the loss of 350 jobs. Some of the museum's scientists say its administrators are turning their backs on its research mission.

Staff at the Conservation and Research Center in Front Royal, Virginia, a conservation biology facility employing 80 people, learned last week that it is to close by the end of the year. The centre conducts research on endangered species and breeding programmes under the auspices of the National Zoo, which is part of the Smithsonian complex.

Also to close is the Smithsonian Center for Materials Research and Education, which employs a smaller number of researchers developing new techniques for preserving museum artefacts.

Scientists fear that the Smithsonian will continue to cut its research activities. According to one senior researcher, who recently left the institution and wished not to be named, the announcement is "the first shoe of probably many ... this is a centipede".

The changes are "shocking and frighten-

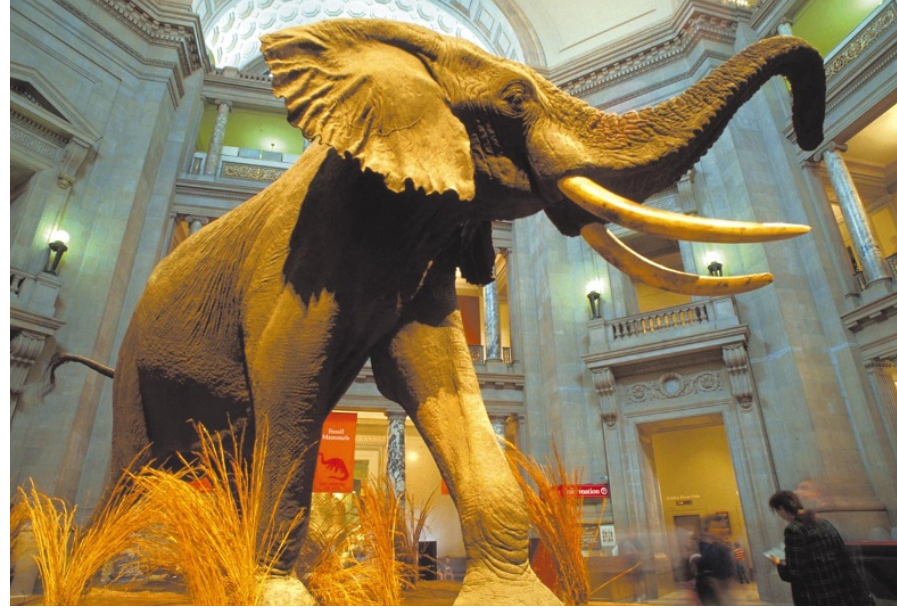

Mammoth attraction: the Smithsonian Institution's funding sources tend to prefer popular exhibits to research

ing for science", says Brian Huber, a palaeobiologist at the National Museum of Natural History and chair of the Smithsonian's academic senate. The senate will meet on 16 April to discuss the plans, but has no power to reverse them. They are likely to be confirmed by the Smithsonian's Board of Regents when it meets in May.

The Smithsonian Institution was set up

\section{UK foot-and-mouth epidemic slows}

Jim Giles, London

The foot-and-mouth outbreak in Britain might at last have peaked, say the government's scientific advisers.

Epidemiologists working with the Ministry of Agriculture, Fisheries and Food (MAFF) say that a levelling off in the number of new cases being reported every day indicates that the disease may now be coming under control.

Last month, three independent groups of researchers told the government that rapid slaughter of infected animals and those on neighbouring farms was the best way to slow the outbreak (see Nature 410, 501; 2001). MAFF says that infected animals are now being slaughtered about 36 hours after they are identified, compared with the previous delay of two or three days.
"We are much more confident now than we were last week that it has peaked," says Neil Ferguson, an epidemiologist at Imperial College, London, who is advising MAFF.

But the precautionary cull might also be artificially lowering the number of new cases. Some new outbreaks will be unreported as the animals are killed before they are diagnosed. The epidemiologists working with MAFF say that the picture will be clearer by the beginning of next week.

Hopes for a speedy end to the outbreak receded last weekend, when new cases were identified in two previously unaffected areas. Government vets confirmed that the virus has spread into South Wales from infected areas in the north. The disease has also spread east and west from a pocket of infection in southern Scotland. in 1846 with funds bequeathed by James Smithson, an English chemist and geologist, to promote "the increase and diffusion of knowledge". But its annual operating budget of almost \$600 million comes from the US Congress and from private donors - both of which tend to attach more importance to popular exhibits than to research.

Researchers at the museum complex believe that Larry Small, a former banker who was appointed last year as the first nonacademic to serve as the Smithsonian's secretary, is behind the changes. "I feel strongly that Larry Small is not the right person to be in charge of the Smithsonian," says David Swofford, an evolutionary biologist who is leaving the natural-history museum for a post at Florida State University. "Morale is lower than it has ever been."

Dennis O'Connor, undersecretary of science at the complex, declined to comment on the closures, which are part of the 2002 federal budget proposal that was announced on Monday (see page 731). The overall budget for the museum complex is set to grow modestly in 2002, however.

A memo issued by Lucy Spelman, director of the National Zoo, says that the conservation centre's closure is a result of budget constraints. But the memo twice mentions that funds released by the closure will be redirected to support public services at the Smithsonian. 